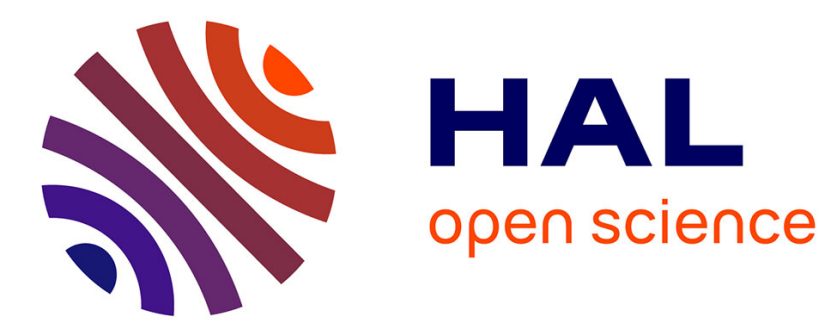

\title{
Experimental \& Numerical Study of the Hot Upsetting of Weld Cladded Billets
}

\author{
Jingcai Wang, Laurent Langlois, Muhammad Rafiq, Régis Bigot, Hao Lu
}

\section{To cite this version:}

Jingcai Wang, Laurent Langlois, Muhammad Rafiq, Régis Bigot, Hao Lu. Experimental \& Numerical Study of the Hot Upsetting of Weld Cladded Billets. 16th annual ESAFORM Conference on Material Forming, Apr 2013, Aveiro, Portugal. pp.287-299, 10.4028/www.scientific.net/KEM.554-557.287 . hal-01103587

\section{HAL Id: hal-01103587 \\ https://hal.science/hal-01103587}

Submitted on 4 Feb 2015

HAL is a multi-disciplinary open access archive for the deposit and dissemination of scientific research documents, whether they are published or not. The documents may come from teaching and research institutions in France or abroad, or from public or private research centers.
L'archive ouverte pluridisciplinaire HAL, est destinée au dépôt et à la diffusion de documents scientifiques de niveau recherche, publiés ou non, émanant des établissements d'enseignement et de recherche français ou étrangers, des laboratoires publics ou privés. 


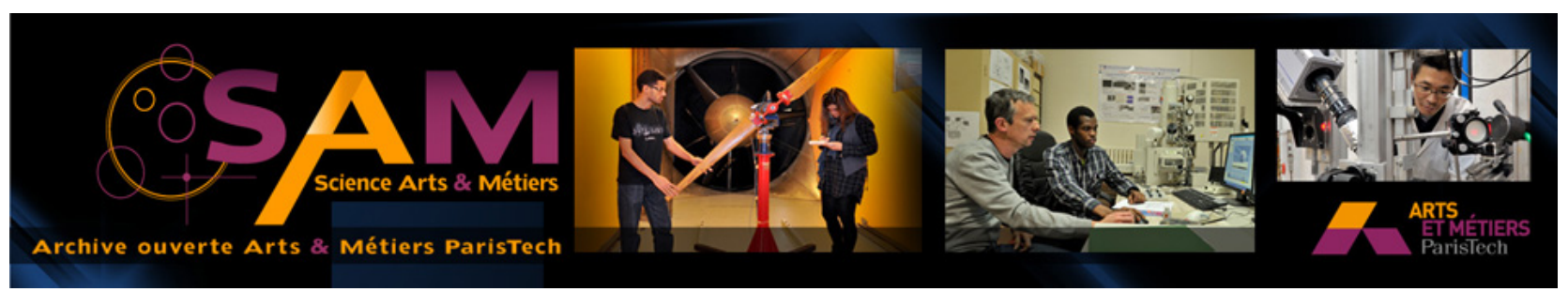

Science Arts \& Métiers (SAM)

is an open access repository that collects the work of Arts et Métiers ParisTech researchers and makes it freely available over the web where possible.

This is an author-deposited version published in: http://sam.ensam.eu

Handle ID: .http://hdl.handle.net/10985/9234

\section{To cite this version :}

Jingcai WANG, Laurent LANGLOIS, Muhammad RAFIQ, Régis BIGOT, Hao LU - Experimental \& Numerical Study of the Hot Upsetting of Weld Cladded Billets - In: 16th annual ESAFORM Conference on Material Forming, Portugal, 2013-04-22 - ESAFORM 2013 /Key Engineering Materials - 2013 


\title{
Experimental \& Numerical Study of the Hot Upsetting of Weld Cladded Billets
}

\author{
Jingcai WANG ${ }^{1,2, a}$, Laurent LANGLOIS ${ }^{1, b}$, Muhammad RAFIQ ${ }^{1, c}$, \\ Régis BIGOT ${ }^{1, d}$ and Hao $\mathrm{LU}^{2, \mathrm{e}}$ \\ ${ }^{1}$ LCFC, ParisTech, 4 rue Augustin Fresnel, 57070 Metz, France \\ ${ }^{2}$ Welding Engineering Institute of Shanghai Jiao Tong University, 200240 Shanghai, China \\ a jingcai.wang@ensam.eu, ${ }^{b}$ Laurent.langlois@ensam.eu, ${ }^{\circ}$ rafiq387@yahoo.com, \\ ' regis.bigot@ensam.eu, ${ }^{\mathrm{e}}$ luhao@sjtu.edu.cn
}

Keywords: Bimaterial, Forgeability, Stainless steel, Weld cladding

\begin{abstract}
:
The presented work is dedicated to studying the forgeability of bimaterial cladded billet. Hot upsetting tests of cylindrical low carbon steel (C15) billets weld cladded (MIG) by stainless steel (SS316L) are experimentally and numerically studied. Upsetting tests with different upsetting ratios are performed in different tribology conditions at $1050^{\circ} \mathrm{C}$ which is within the better forgeability temperature range of both substrate and cladding materials ${ }^{[1]}$. Slab model and finite-element simulation are conducted to parametrically study the potential forgeability of the bimaterial cladded billet. The viscoplastic law is adopted to model the friction at the die/billet interface. The friction condition at the die/billet interface has a great impact on the final material distribution, forging effort and cracking occurrence. With Latham and Cockcroft Criterion, the possibility and potential position of cracks could be predicted.
\end{abstract}

\section{Introduction}

Bimaterial cladded workpiece could satisfy the complex functional requirements as well as attain a compromise between performances and manufacturing costs. The selection of its manufacturing processes is decided by various elements such as mechanical and metallurgical properties, productivity and costs. The classical fabrication process of cladded products sequentially includes the preform manufacturing, forming process, weld cladding process and finishing process. After the forming process, the preforms become complex to be weld cladded, conducting the problem of low efficiency and bad quality control of the following weld cladding process. The presented work has changed the order of the fabrication process. Performing the weld cladding process before the forming process, a simple preform is weld cladded and then forged to obtain the final complex form required. Higher productivity and better quality control are expected to obtain. At the same time, the final metallurgical structure of the cladding material is optimized by the hot plastic forming. The objective of this article is to study the ability of a weld cladded billet under hot forging to obtain a desired form with defect free material distribution and structure.

A bimetal could fabricate by various process such as diffusion bonding, rolling, extrusion, simultaneous plastic deformation ${ }^{[2]}$, cladding and powder metallurgy technique ${ }^{[3]}$ etc. Mehmet Şimşir et al. have produced a bimetal bulk consisting of stainless steel (SS316L) and structural steel (30CrNiMo8) by shell mold casting technique ${ }^{[4]}$. The authors have characterized the metallurgy and mechanical properties of the bulk, but never the forgeability. Presently, little work is available on the forgeability of bimaterial cladded billet. Joseph Domblesky et al. have studied the forgeability of welded preforms. Two cylindrical billets of same metal and different metals are butted by general friction weld. The authors find that such preforms have adequate workability based on upsetting and side pressing tests, although flow tends to be concentrated in the lower strength alloy for bi-metal preforms ${ }^{[5]}$. Later, the authors investigate the mechanical properties and microstructural evaluation of these forged welded preforms by tensile testing. The results show that for same-metal specimens the 
microhardness and microstructure after hot working are fairly uniform and consistent with the surrounding base metal pieces in the weld vicinity. For the bi-metal ones, an asymmetric hardness gradient is generated ${ }^{[6]}$. K. Essa et al. ${ }^{[7]}$ have done a work similar to the work presented in this paper. The authors have studied the cold upsetting of bi-metallic ring type billets which consists of a solid inner $\mathrm{C} 15 \mathrm{E}$ cylinder and a ring of mild steel (C45E) fitting around the former cylinder by friction. The objective is to find a success process for cold forging of such bi-metallic billets. The results show that under certain conditions, bi-metallic billets may be upset while maintaining a good interfacial contact between the two components within a range of geometries.

The presented work concentrates on the hot forgeability of a low carbon steel (C15) billet coated by austenitic stainless steel (SS316L) by MIG cladding. A series of upsetting tests with different ratios and using different friction conditions at $1050^{\circ} \mathrm{C}$ are performed. Slab model and finite-element model are introduced. Comparison is performed between the experimental results and the numerical results. Upsetting is considered as a forgeability testing of the bi-material. The intended applications concern hot forming of raw preforms like cylindrical billet or flat sheet partially cladded ${ }^{[8]}$.

\section{Upsetting of weld cladded billet}

The hot upsetting test is a basic hot ductility test consisting of compressing a series of cylindrical specimens to various levels. The limit for compression without radial or peripheral cracking is considered to be a measure of forgeability. The upsetting tests are performed to understand the fundamentals of material flow and the initiation of cracking during the deformation to obtain the forgeability limits of cladded specimens.

\section{Principle of experiments}

In the upsetting test, a billet is upset between two plat dies at $1050^{\circ} \mathrm{C}$ until a crack appears. Depending on the appearance of cracks, the upset ratio of the next trial is increased or decreased. The increase or decrease step is adjusted referring to the total specimen height. From the last test without cracks, the upset increment step is reduced to refine the applicable range. The cladded specimens are obtained by cutting a weld cladded bar. A mild steel bar $(0.15 \% \mathrm{C}, 0.45 \% \mathrm{Mn}, 0.2 \% \mathrm{Si}, 0.023 \% \mathrm{P}$ and $0.023 \% \mathrm{~S})$ with a diameter of $\varnothing 27 \mathrm{~mm}$ is cladded by stainless steel $(0.02 \% \mathrm{C}, 1.8 \% \mathrm{Mn}, 0.33 \% \mathrm{Si}, 0.023 \% \mathrm{P}$, $0.013 \% \mathrm{~S}, 17.5 \% \mathrm{Cr}, 2.55 \% \mathrm{Mo}$ and $12.2 \% \mathrm{Ni})$ wire $(\varnothing 1.0 \mathrm{~mm})$ by MIG process on rotating welding platforms. The bar is then cut into $45 \mathrm{~mm}$-high specimens. The main parameters of the MIG cladding process are shown in Table 1.

Table 1 Parameters of MIG cladding process

\begin{tabular}{cccccccc}
\hline Parameters & $\begin{array}{c}\text { Nozzle-to-bar } \\
\text { distance } \\
{[\mathrm{mm}]}\end{array}$ & $\begin{array}{c}\text { Wire } \\
\text { feed } \\
\text { speed } \\
{[\mathrm{mm} / \mathrm{s}]}\end{array}$ & $\begin{array}{c}\text { Voltage } \\
{[\mathrm{V}]}\end{array}$ & $\begin{array}{c}\text { Welding } \\
\text { speed } \\
{[\mathrm{mm} / \mathrm{s}]}\end{array}$ & $\begin{array}{c}\text { Protection } \\
\text { gas [\% in } \\
\text { volume }]\end{array}$ & Generator & $\begin{array}{c}\text { Welding } \\
\text { machine }\end{array}$ \\
\hline Value & 16 & 4.2 & 22 & 5.3 & $\begin{array}{c}\mathrm{Ar} 96 \%, \\
\mathrm{CO}_{2} 3 \%, \\
\mathrm{H}_{2} 1 \%\end{array}$ & CY385MPR & $\begin{array}{c}\text { 6-axes } \\
\text { polyarticular } \\
\text { robot (SCS) }\end{array}$ \\
\hline
\end{tabular}

Fig. 1 shows the longitudinal section of the cladded billet. The substrate/cladding interface exhibits a wavy morphology. The mean cladding thickness is about $3 \mathrm{~mm}$. For a billet of $45 \mathrm{~mm}$, there are about 10 beads. The cladding is composed of juxtaposed bead rings instead of a coil. There is an overlapping on the beginning of the bead by the end of the same bead. The overall dilution rate between the filler material and the substrate is about $10 \%$. This relatively low value for MIG cladding is achieved owing to overlapping. 


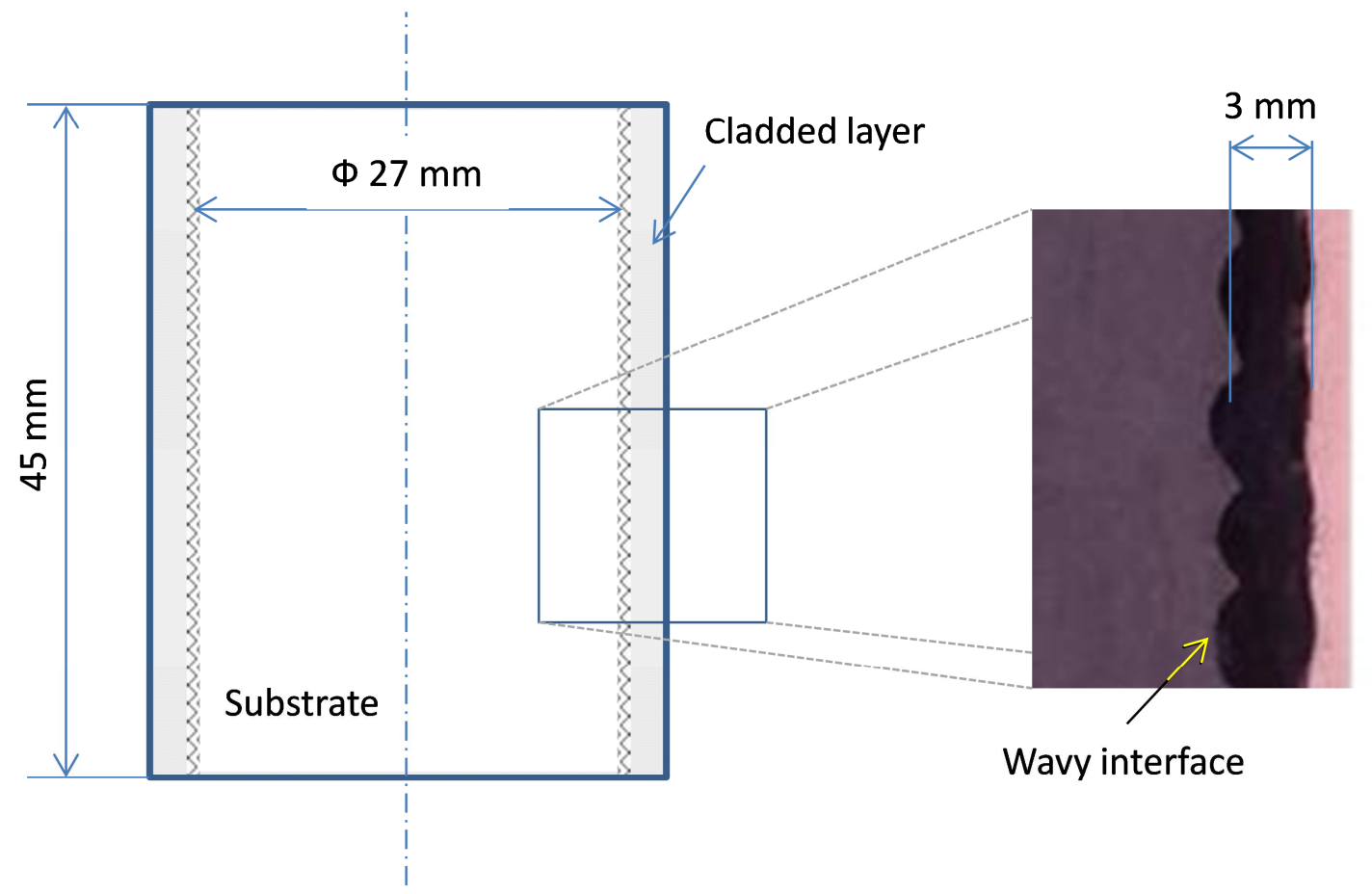

Fig. 1 The longitudinal section of a weld cladded specimen

The upsetting tests were performed on a hydraulic press machine, with a mark of Loire ACB, with a maximum load of $6000 \mathrm{kN}$. The specimens were heated 15 minutes at $1050^{\circ} \mathrm{C}$ under normal atmosphere in an electric furnace, while the dies were not preheated. The tribological condition at the die/billet interface was an input of the experimental parametric study. Therefore, the tests were performed with lubricated and dry smooth dies as well as striated dies. Theses dies respectively corresponded to low, strong and sticking friction on the die/billet interface. The lubricant was a mixture of water and graphite. It was deposited on the smooth die by a brush before each test. There are many concentric circular grooves on the plan of the striated die. The distance between two successive grooves was about $1 \mathrm{~mm}$ with a depth of $1 \mathrm{~mm}$. The specimens were taken out of the furnace and upset immediately. The upset velocity was constant about $30 \mathrm{~mm} / \mathrm{s}$. The specimen was upset to various ratios with the help of stop blocks placed between the die holders.

\section{Modelling}

The upsetting test is also studied numerically. This part is devoted to study the crack occurrence in bi-material cladded billet, estimate the material distribution, predict the forging effort and evaluate the effect of process parameters.

\section{a. Slab model}

The slab model, based on classical slab model of non-cladded billet upsetting, integrates the continuity condition through substrate/cladding interface. Fig. 2 shows the geometrical and other parameters of the model. A viscoplastic law is applied for modelling the friction condition at the die/billet interface. 


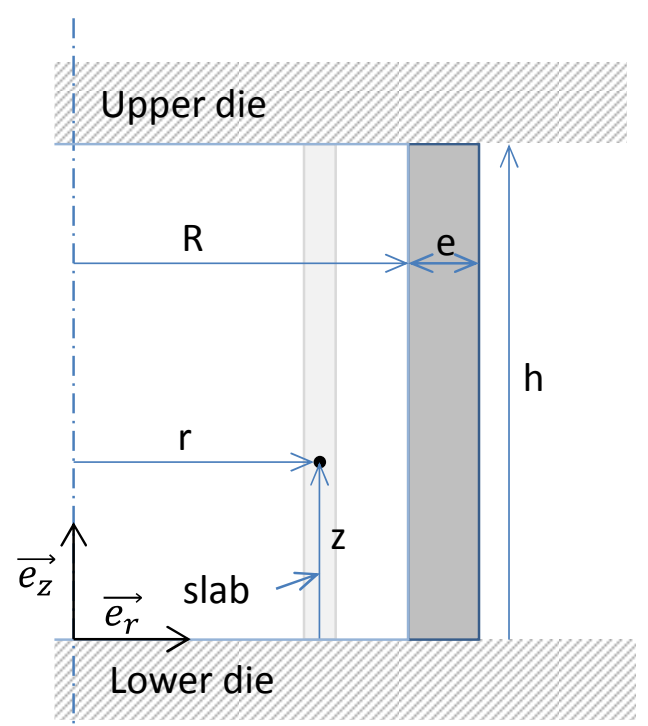

Fig. 2 Slab model of weld cladded billet

The slab model is based on several assumptions:

- The cladded billet and the substrate/cladding interface remain cylindrical during the deformation;

- The temperature of the billet is constant and uniform during the upsetting; thermal exchange with dies and dissipated energy are neglected;

- The material behavior can be modeled by a simplified Spittel thermo-viscoplastic law;

- Plasticity can be governed by the von Mises criterion;

- Friction at die/billet interface can be represented by a viscoplastic law.

According to the cylindrical symmetry and considering the mass conservation principle, the velocity field is obtained as below:

$$
\overrightarrow{\mathrm{v}}(\mathrm{r}, \mathrm{z})=-\frac{\mathrm{r}}{2 \mathrm{~h}} \overrightarrow{\mathrm{e}_{\mathrm{r}}}+\mathrm{z} \cdot \frac{\dot{\mathrm{h}}}{\mathrm{h}} \overrightarrow{\mathrm{e}}
$$

where $\dot{h}$ is constant and corresponds to the upsetting velocity. The magnitude of the sliding speed at die/billet interface during the deformation is as below:

$$
\mathrm{v}_{\mathrm{g}}=\frac{\mathrm{r}|\dot{\mathrm{h}}|}{2 \mathrm{~h}}
$$

The plastic strain rate is uniform in the cladded billet and given by Eq. 3 .

$$
\dot{\varepsilon}^{p}=\left(\begin{array}{ccc}
-\frac{1}{2} & 0 & 0 \\
0 & -\frac{1}{2} & 0 \\
0 & 0 & 1
\end{array}\right) \frac{\dot{h}}{\mathrm{~h}}
$$

The equivalent plastic strain is given by Eq. 4.

$$
\varepsilon=\ln \left(\frac{\mathrm{h}_{0}}{\mathrm{~h}}\right)
$$

where $\mathrm{h}_{0}$ is the initial height of the billet.

In order to get the stress tensor of billet, von Mises plasticity criterion is applied with conditions that the deviatory stress is parallel to strain rate and the equivalent stress is equal to the flowing stress of the material. In this condition, one can get: 


$$
\sigma=\left(\begin{array}{ccc}
\sigma_{\mathrm{rr}} & 0 & 0 \\
0 & \sigma_{\mathrm{rr}} & 0 \\
0 & 0 & \sigma_{\mathrm{rr}}-\sigma_{0}
\end{array}\right)
$$

Where $\sigma$ is the complete stress tensor, $\sigma_{0}$ is the flow stress of the material and $\sigma r r$ is the normal stress in the radial direction.

The fundamental principle of applied statics is applied to the slab bounded by:

$$
r \in[r, r+d r] ; \quad \theta \in\left[\theta-\frac{d \theta}{2}, \theta+\frac{d \theta}{2}\right] ; \quad z \in[0, h]
$$

Considering the following equilibrium in the direction $\overrightarrow{\mathrm{e}_{\mathrm{r}}}$ :

$$
\mathrm{h}\left(\sigma_{\mathrm{rr}}+\mathrm{d} \sigma_{\mathrm{rr}}\right)(\mathrm{r}+\mathrm{dr}) \mathrm{d} \theta-\mathrm{hr} \sigma_{\mathrm{rr}} \mathrm{d} \theta-2 \mathrm{~h} \sigma_{\mathrm{rr}}\left(\sin \frac{\theta}{2}\right) \mathrm{dr}-2 \tau \mathrm{rdrd} \theta=0
$$

Where $\tau$ is the tangential stress at the die/billet interface corresponding to friction. $\tau$ is negative and opposes the sliding of material on the die. Developing the relationship of order 2 one can get:

$$
\mathrm{d} \sigma_{\mathrm{rr}}=-2 \frac{\tau}{\mathrm{h}} \mathrm{dr}
$$

The relation between the friction stress and the thermomechanical conditions at die/billet interface is modeled by a viscoplastic law:

$$
\tau=-\alpha \sigma_{0} \mathrm{v}_{\mathrm{g}} \mathrm{P}_{\mathrm{f}}
$$

where $\alpha$ is the friction factor, $\sigma_{0}$ is the flowing stress and $P_{f}$ is the friction exponent. According to Eq. 2,10 and 11 , the general expression of the radial stress is given as:

$$
\sigma_{\mathrm{rr}}=\mathrm{K} \sigma_{0} \cdot \mathrm{r}^{\mathrm{P}_{\mathrm{f}}+1}+\mathrm{C}
$$

where $C$ is an integrating constant and $\mathrm{K}$ is given by Eq. 13 .

$$
\mathrm{K}=\alpha \cdot \frac{2^{1-\mathrm{P}_{\mathrm{f}}}}{\mathrm{h}} \cdot\left(\frac{\dot{\mathrm{h}}}{\mathrm{h}}\right)^{\mathrm{P}_{\mathrm{f}}} \cdot \frac{1}{\mathrm{P}_{\mathrm{f}}+1}
$$

According to the considered zone in the billet (substrate or cladded layer), the value of $K, \sigma_{0}, P_{f}$ and $C$ of Eq. 12 have to be adapted.

The radial stress is continuous through the susbtrate/cladding interface and is equal to zero at the external free surface of the billet. Considering these boundary conditions, Eq. 12 leads to:

$$
\begin{aligned}
& \sigma_{r r}=K\left(\sigma_{0 s} r^{P_{f}+1}+\left(\sigma_{0 r}-\sigma_{0 s}\right) R^{P_{f}+1}-\sigma_{0 r}(R+e)^{P_{f}+1}\right) r \in[0, R] \\
& \sigma_{r r}=K \sigma_{0 r}\left(r^{P_{f}+1}-(R+e)^{P_{f}+1}\right) r \in[R, R+e]
\end{aligned}
$$

Considering the axi-symetry of the problem,the forging effort is given by the following equation:

$$
\mathrm{F}=-2 \pi \int_{0}^{\mathrm{R}+\mathrm{e}} \sigma_{\mathrm{zz}} \mathrm{rdr}
$$


The axial stress $\sigma_{z z}$ is function of the flowing stress and the radial stress as it can be seen in Eq. 5 . Finally, the forming load is given by Eq. 17.

$$
\begin{gathered}
F=\frac{2 \pi K}{P_{f}+3}\left(R^{P_{f}+3}\left(\sigma_{0 r}-\sigma_{0 s}\right)-\sigma_{0 r}(R+e)^{P_{f}+3}\right)+\pi R^{2}\left(\sigma_{0 s}-C_{s}\right) \\
+\pi e(2 R+e)\left(\sigma_{0 r}-C_{r}\right)
\end{gathered}
$$

With

$$
\begin{aligned}
& C_{s}=K\left(\left(\sigma_{0 r}-\sigma_{0 s}\right) R^{P_{f}+1}-\sigma_{0 r}(R+e)^{P_{f}+1}\right) \\
& C_{r}=-K \sigma_{0 r}(R+e)^{P_{f}+1}
\end{aligned}
$$

$R$ and $e$ are functions of the initial geometry $\left(h_{0}, e_{0}, R_{0}\right)$ of the billet and the upsetting height. According to the principle of volume conservation:

$$
\begin{aligned}
& \mathrm{R}=\mathrm{R}_{0} \sqrt{\frac{\mathrm{h}_{0}}{\mathrm{~h}}} \\
& \mathrm{e}=\mathrm{e}_{0} \sqrt{\frac{\mathrm{h}_{0}}{\mathrm{~h}}}
\end{aligned}
$$

The flowing stress of the substrate could be calculated from the equivalent plastic strain and strain rate. It's described by a simplified Hansel-Spittel law (see Eq. 22) that is well suited to represent the hot forming behavior of metals:

$$
\sigma_{0}=A \cdot \exp \left(\mathrm{m}_{1} \mathrm{~T}\right) \cdot \varepsilon^{\mathrm{m}_{2}} \cdot \dot{\varepsilon}^{\mathrm{m}_{3}} \cdot \exp \left(\frac{\mathrm{m}_{4}}{\varepsilon}\right)
$$

The law with associated coefficients is only valid for given range of temperatures, strain and strain rate data for each material.

The forging effort, calculated by the slab model, depends only on:

- The initial geometry of the cladded billet $\left(h_{0}, e_{0}, R_{0}\right)$

- The friction factor at the die/billet interface

- The flowing stress of the two materials

\section{b. Finite-element model}

The finite-element model is implemented on the platform of Forge2011®. Considering the symmetry of the problem, a 2-D axe-symmetric hot forging model is adopted. The rheological law used by the software is a simplified Hansel-Spittel law in the form of equation (22). The bilateral sticking criterion is applied to the substrate/cladding interface although there is practically weld cladding interface between them. A high heat exchange coefficient $\left(2 \times 10^{4} \mathrm{Wm}^{-2} \mathrm{~K}^{-1}\right)$ is applied in order to reduce the temperature discontinuity at the interface regardless of the heat flux.

Special attention is paid on the substrate/cladding interface geometry, refining the grids of the interface zone in order to better control the continuity conditions through the interface. The simulation model is shown in Fig. 3. Two types of substrate/cladding interface, cylindrical and wavy (sine) morphology, are adopted and compared in the study. The latter is implemented in order to estimate the effect of the wavy morphology of the substrate/cladding interface. Fig. 3 also shows the geometrical parameters of the sine-wavy interface. 
Sine curve interface
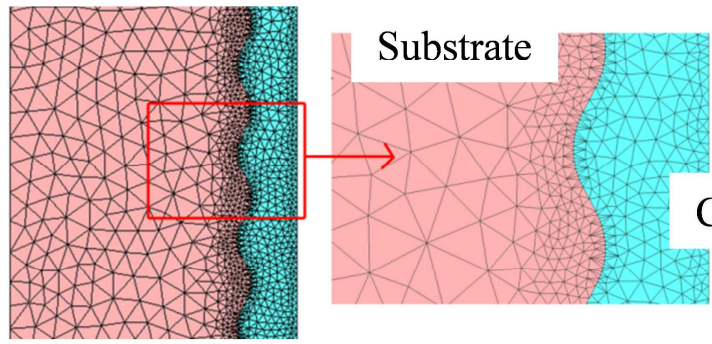

Cladded layer interface

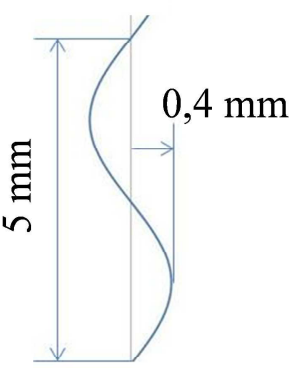

Straight

interface

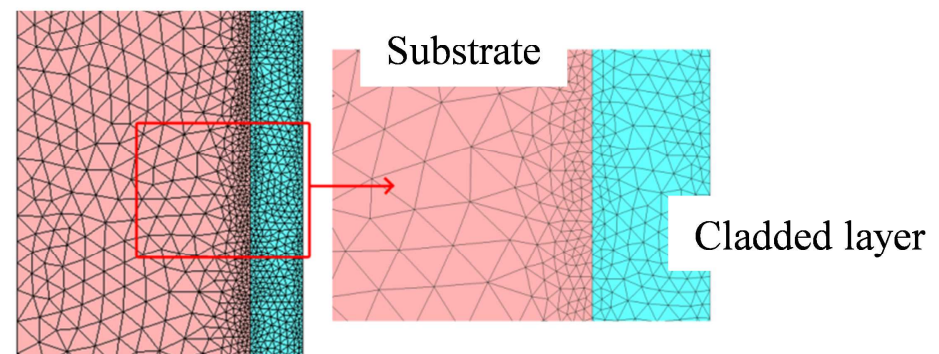

Fig. 3 Model with sine curve interface and model with straight interface

A weak heat exchange $\left(2 \times 10^{3} \mathrm{Wm}^{-2} \mathrm{~K}^{-1}\right)$ is applied to the die/billet interface. The tribology is described by viscoplastic law. The dies are considered to be rigid.

\section{c. Simulation parameters}

The coefficients of the Spittel law of the substrate and cladding materials for slab model and finite element simulation are given in Table 2. They are extracted from the Forge $2011{ }^{\circledR}$ database and correspond to thermo-viscoplastic behavior of low carbon steel C15 and stainless steel SS316L. The effects of dilution resulting from the cladding process are neglected.

Table 2 Coefficients of Hansel-Spittel Law for hot upsetting simulation

\begin{tabular}{llcccc}
\hline \multirow{2}{*}{ Material } & \multicolumn{5}{c}{ Coefficients of simplified Hansel-Spittel Law } \\
\cline { 2 - 6 } & $\mathrm{A}(\mathrm{Mpa})$ & $\mathrm{m}_{1}$ & $\mathrm{~m}_{2}$ & $\mathrm{~m}_{3}$ & $\mathrm{~m}_{4}$ \\
\hline C15 & 890.4543 & -0.00234 & -0.12626 & 0.13938 & -0.0477 \\
SS316L & 8905.34 & -0.00383 & 0.01246 & 0.09912 & -0.02413 \\
\hline
\end{tabular}

Three levels of friction conditions are considered. The sticking condition, corresponding experimentally to upsetting tests performed with striated dies, cannot be taken into account by the slab model. For the upsetting tests performed with dry and lubricated smooth dies, the parameters of the viscoplastic friction law are given in Table 3.

Table 3 Parameters of the hydraulic press

\begin{tabular}{ccc}
\hline Friction conditions & $\alpha$ & $\mathrm{P}_{\mathrm{f}}$ \\
\hline Lubricated die & 0.3 & 0.15 \\
Dry die & 0.5 & 0.15 \\
\hline
\end{tabular}

The forming velocity is $30 \mathrm{~mm} / \mathrm{s}$. The initial dimensions of the cladded billet are given in Fig. 1. For finite element calculation, a dwell time of 5 seconds is introduced before upsetting in order to take into account the experimentally unavoidable time between the moment when the billet is placed on the lower die and the moment when the upsetting starts.

\section{Results and discussion}


With experimental and numerical studies, the final results of hot upsetting tests of weld cladded billet are analyzed. The analysis is focused on the material distribution, forming load and hot damage generated during deformation. The slab model results only concern the forming load.

\section{Material distribution}

Fig. 4 shows the material distribution obtained experimentally and after finite element calculation. The longitudinal cross section of upset cladded billets are etched by Nital $2 \%$ for a few seconds. The material distribution is observed visually in the macrographs of longitudinal section as shown in Fig. 4. The hot forged substrate consists of a central trunk surrounded by a ring covered by the deformed cladded layer.

The material distribution varies with the tribology condition at the die/billet interface. The elongation of the cladded layer depends on the tribological conditions. The cladded layer becomes thinner or thicker after upsetting. In the case of sticking conditions the layer is thinned during forming. The obtained thickness is no more uniform (see Fig. 4). A zone with cladded layer thinning can be observed experimentally and by finite element simulation for tests performed with striated dies. The dissymmetry of material distribution between the upper and lower surface might be caused by the dwell time (about 5 seconds) between placing the billet on the lower die and forging. The billet has heat exchange with the lower die during the dwell time. Therefore, the material in the lower part of the billet is colder, causing larger flowing stress. This phenomenon emphasizes the important effect of heat exchange on material distribution of hot-upset cladded billet.
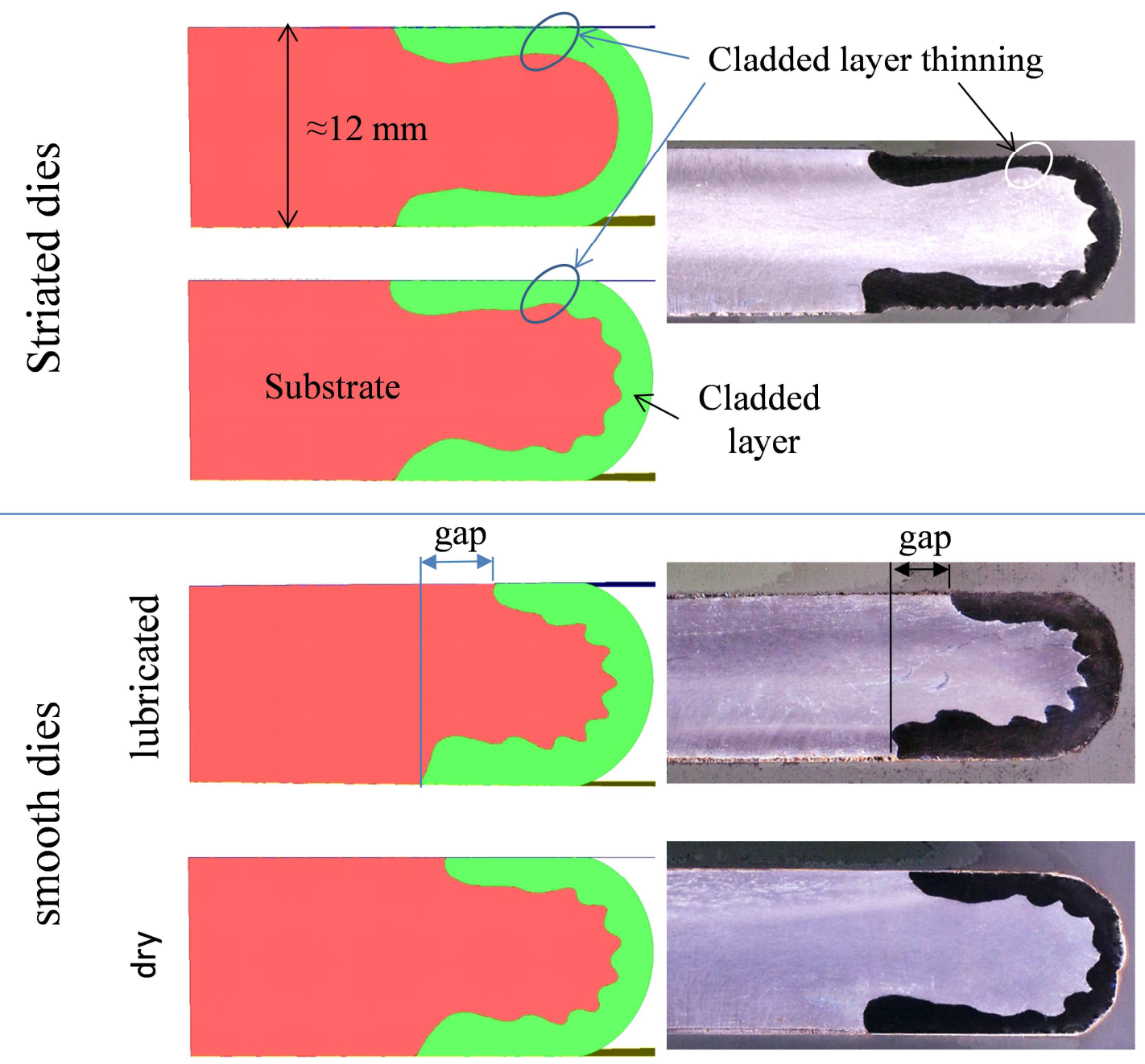

Fig. 4 Comparison of numerical and experimental results of materials distribution obtained with striated die (corresponding to sticking friction), lubricated and dry smooth dies 
The finite element simulation is able to predict the material distribution, the effect of friction conditions and thermal exchange with the tool. The modeling of the wavy morphology of the bimaterial interface is necessary for accurate prediction of the thickness of cladded layer and to observe the detail shape of the interface. However, the overall distribution of the materials can be also predicted with smooth interface model as shown in Fig.4.

\section{Forming load}

The evolution of forming load is traced experimentally and numerically. Comparisons are performed to evaluate the slab model and simulation model.

Experimentally, the forming load and displacement of upper die are directly provided by the sensors in the hydraulic press machine. The forging effort is calculated from the pressure in the main cylinder of the machine with a precision corresponding to about $\pm 5 \mathrm{kN}$. Fig. 5 shows the evolution of forging effort for tests performed with different types of dies.

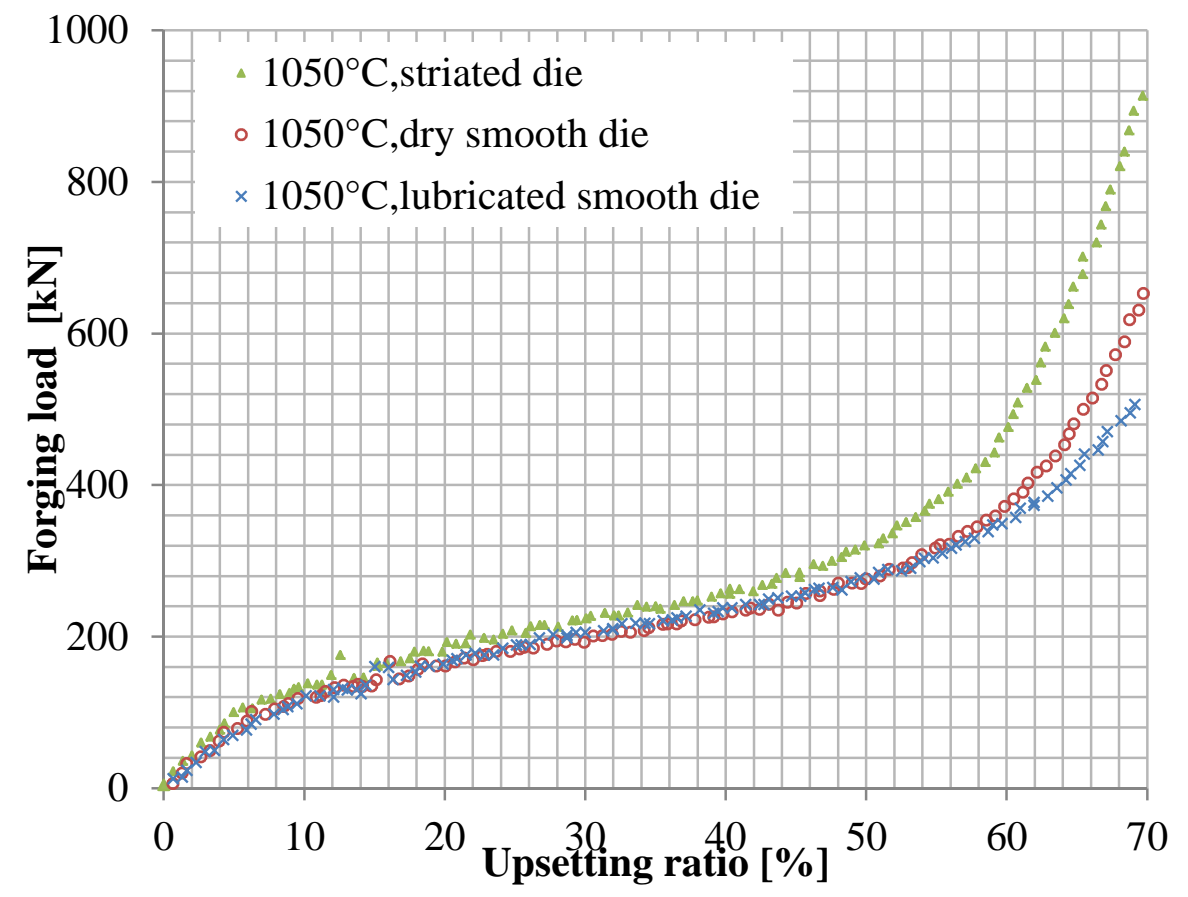

Fig. 5 Evolution of forging efforts for tests performed with different types of dies

The forging load-versus-displacement curves are quite similar to that of mono-material billet upsetting. At the end of the test, forming load increases sharply because of many factors: the increase of the billet diameter, the deformation rate increases during the forging (the forming velocity being constant), the accumulation of friction forces leading to an increase in hydrostatic pressure and the cooling of the billet with thermal exchange. The effect of friction condition is similar to that of upsetting of mono-material. The higher the friction conditions are the higher the forming load is for a given upsetting rate.

Slab model and simulation are able to reproduce the effect of friction on the forming load. The developed slab model is not able to simulate sticking condition. The evolution of forging efforts is similar to the experimental result; the effect of friction factor is more sensitive at the end of upsetting. 

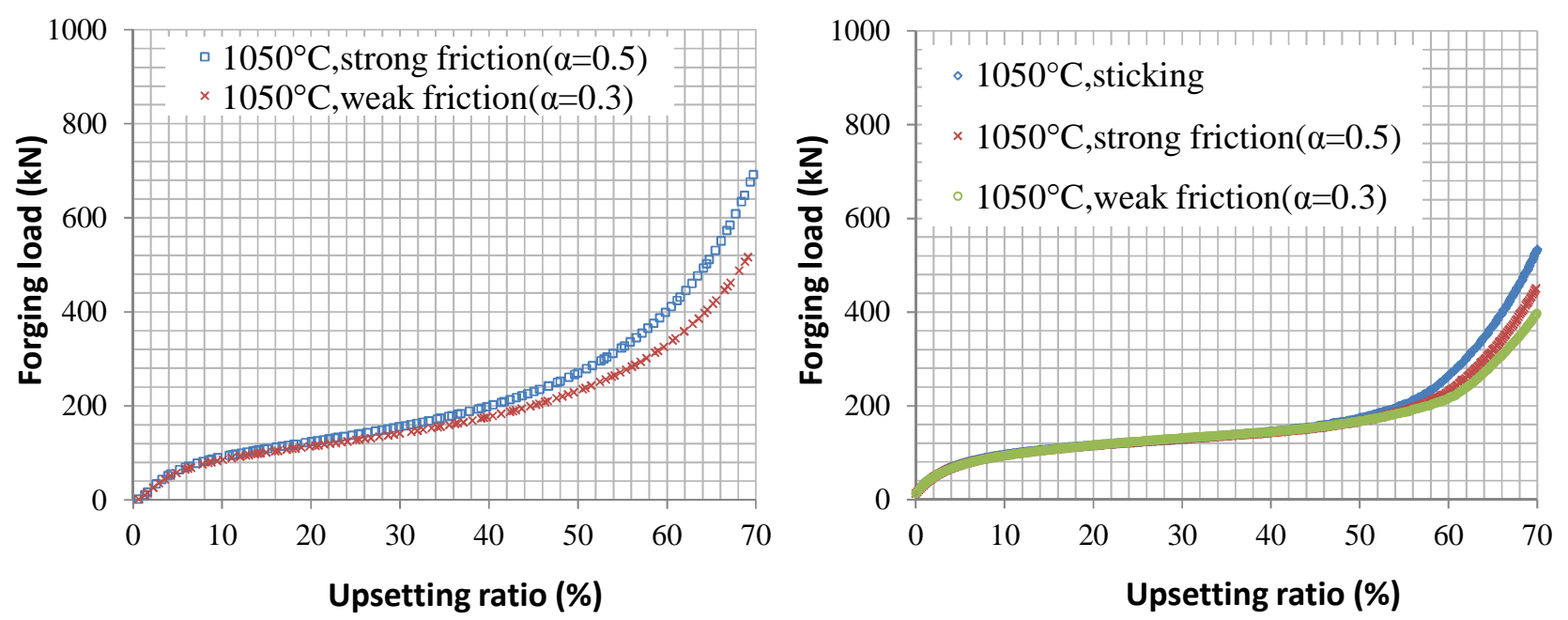

Fig. 6 Evolution of forging efforts (a) for slab model, (b) for finite element model with wavy interface

For finite element model, there is no notable difference concerning the forming load obtained with the smooth and wavy substrate/cladded layer interface.

Compared with the simulation results, the forming load obtained by slab model is higher. This is a well-known result, the kinematical assumption for slab model leading to overestimation of the stress and the associated forming load.

In Fig. 7, one can note that the forming load measured experimentally between 5\% and 50\% is higher than that of finite element simulation or slab model. The difference is not caused by bad friction coefficient because its effect is mainly sensitive at the end of the upsetting. It might be due to the fact that the behavior of the cladded layer is modeled by the Spittel law of SS316L without considering the effect of dilution. In order to better estimate the forming load, it would be necessary to identify the behavior law of the cladded material.
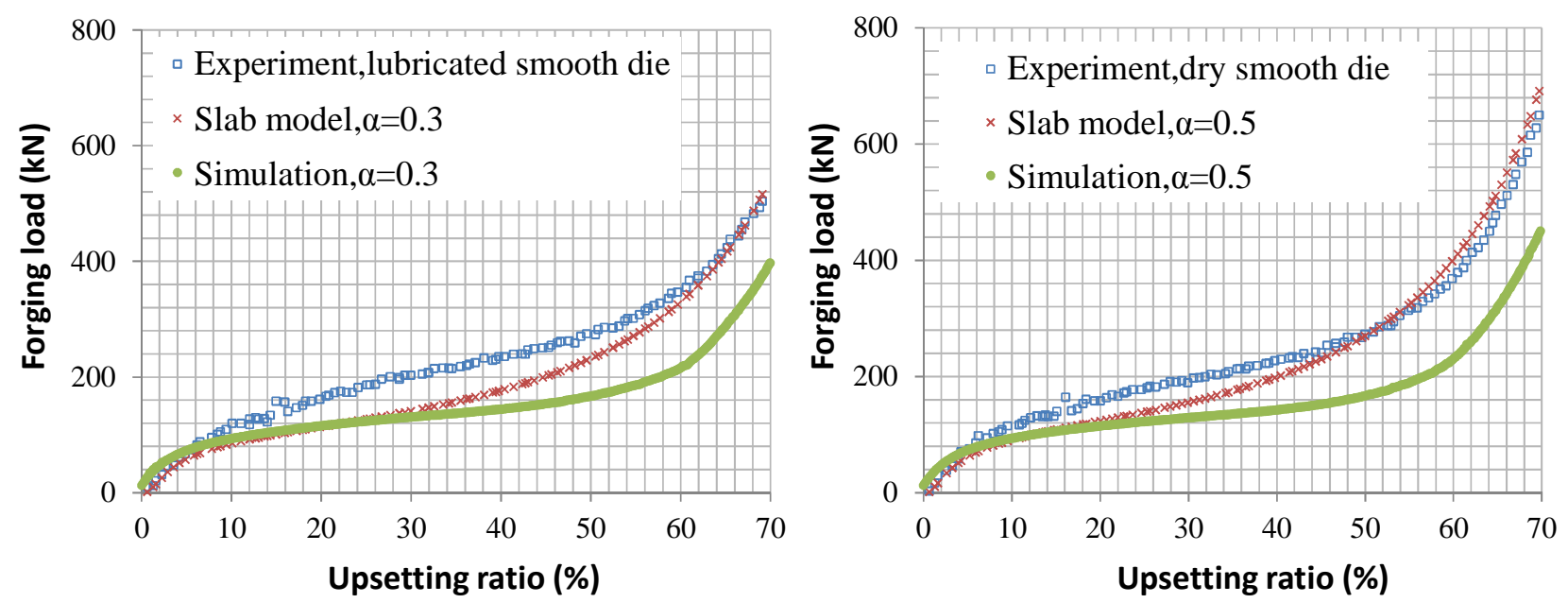

Fig. 7 Comparison of experiment, slab model and simulation

\section{Hot damage}

Longitudinal and circumferential cracks, which occur only in the cladded layer and never propagate into the substrate, are observed on billet upset with striated dies at an upsetting ration around 70\% (see Fig. 8). The circumferential cracks locate in the thinnest zone of the cladded layer on the top or lower surface of the billet. For smooth dies, lubricated or not, only longitudinal cracks are observed in tests with upsetting ratios higher than $70 \%$. Circumferential cracks are specific feature for cladded billet. 


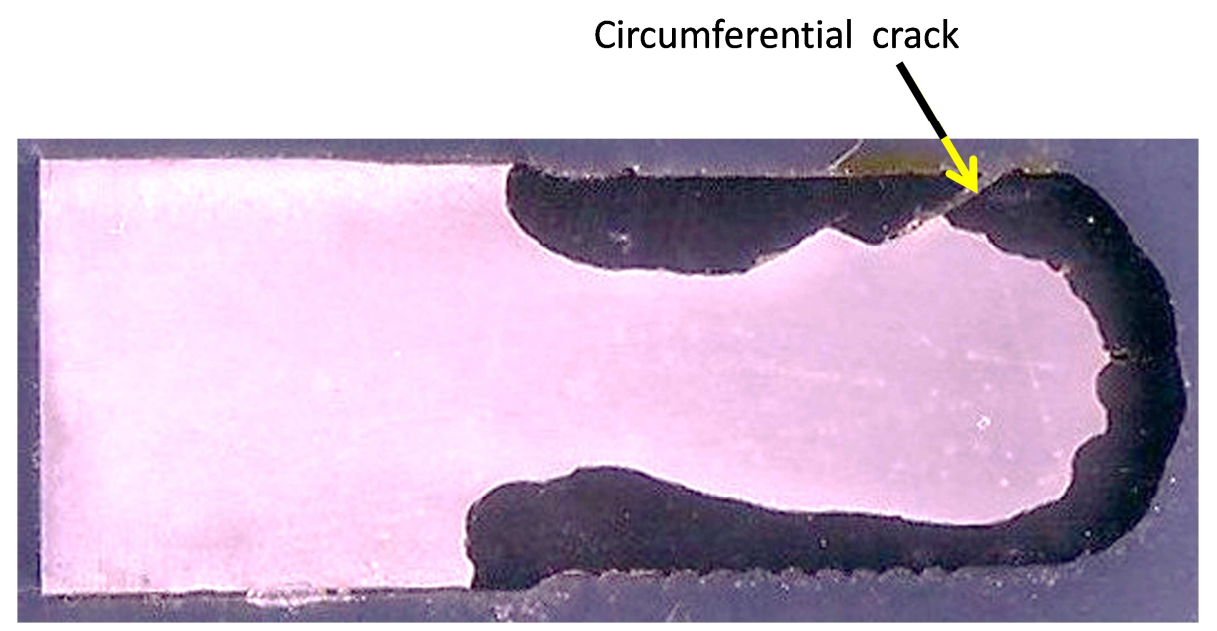

Fig. 8 Section of billet upset at $1050^{\circ} \mathrm{C}$ with striated die

In Forge $2011 \circledR$, it is possible to estimate the probability of the damage of billet by calculating the Latham and Cockcroft coefficient. The indicator $L a$ is used to predict crack occurrence. Its expression is given by Eq. 23:

$$
\mathrm{La}=\int_{0}^{\varepsilon} \frac{\sigma_{\mathrm{max}}}{\sigma_{\mathrm{eq}}} \mathrm{d} \varepsilon
$$

Where $\varepsilon$ is the effective strain, $\sigma_{\max }$ is the maximum principal stress if it's positive; otherwise it's equal to zero. $\sigma_{e q}$ is the von Mises equivalent stress.

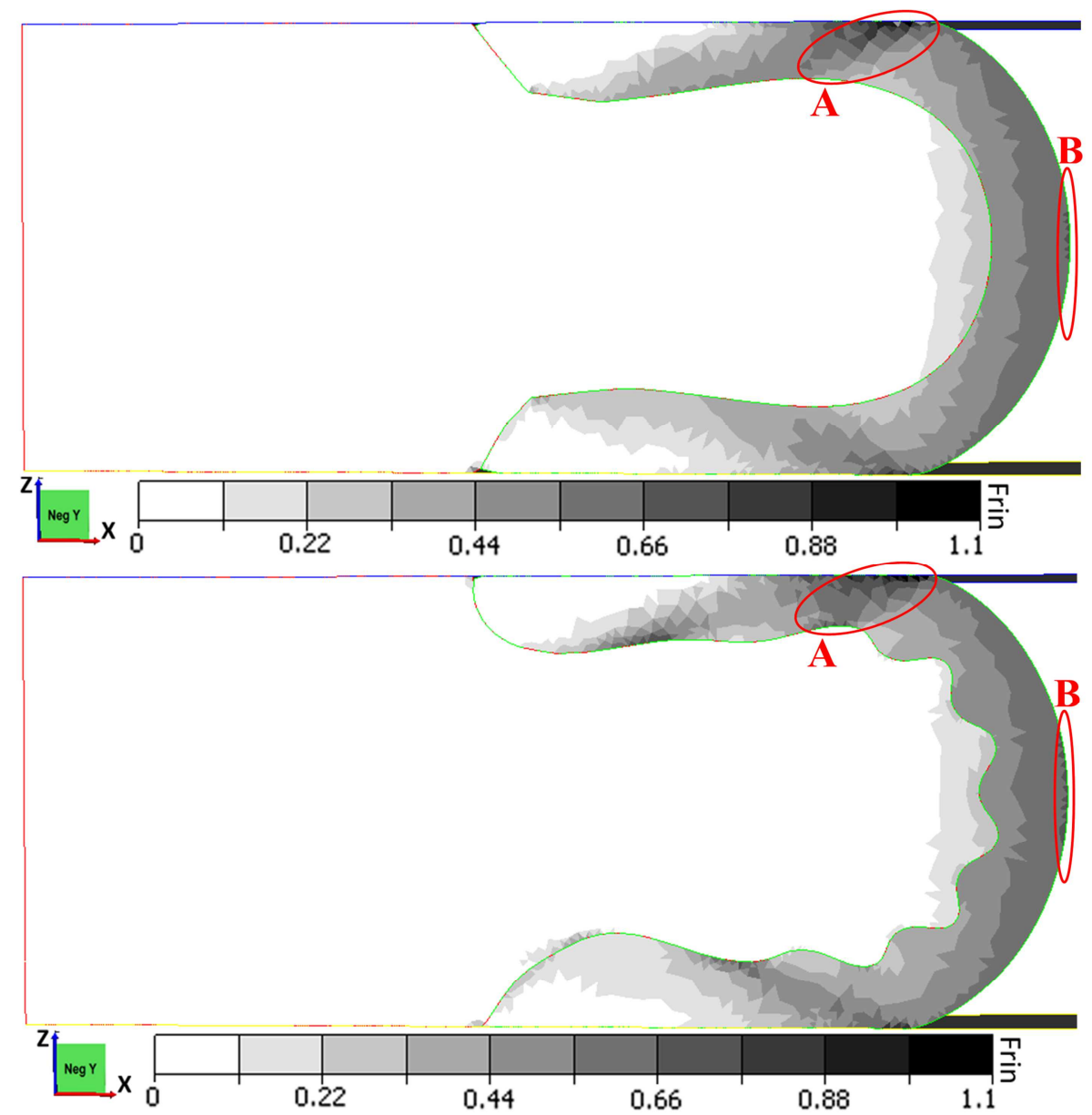

Fig. 9 Distribution of indicator $L a$ for simulation with sticking friction 
The probability of crack occurrence increases if the value of the indicator $L a$ is larger. According to Fig. 9, the Zone A and B are places with maximum values of $L a$. Zone B corresponds to longitudinal crack and Zone A to circumferential cracks. The configuration of substrate/cladded layer interface impacts little the overall distribution of $L a$. The occurrence and the location of circumferential cracks could be predicted even with smooth interface model.

With Forge 2011®, the evolution of $L a$ for certain grids in Zone A and B are drawn (see Fig. 10). For $70 \%$ upset, the value of $L a$ in Zone A is larger than that in Zone B. The two curves intersect at the point where the upsetting ratio is slightly less than $70 \%$. The simultaneous occurrence of two types of cracks in the billet tends to give the critic value of $L a$ for the hot ductility of the cladded billet at $1050^{\circ} \mathrm{C}$. According to Fig .10, the critic value is close to 0.6.
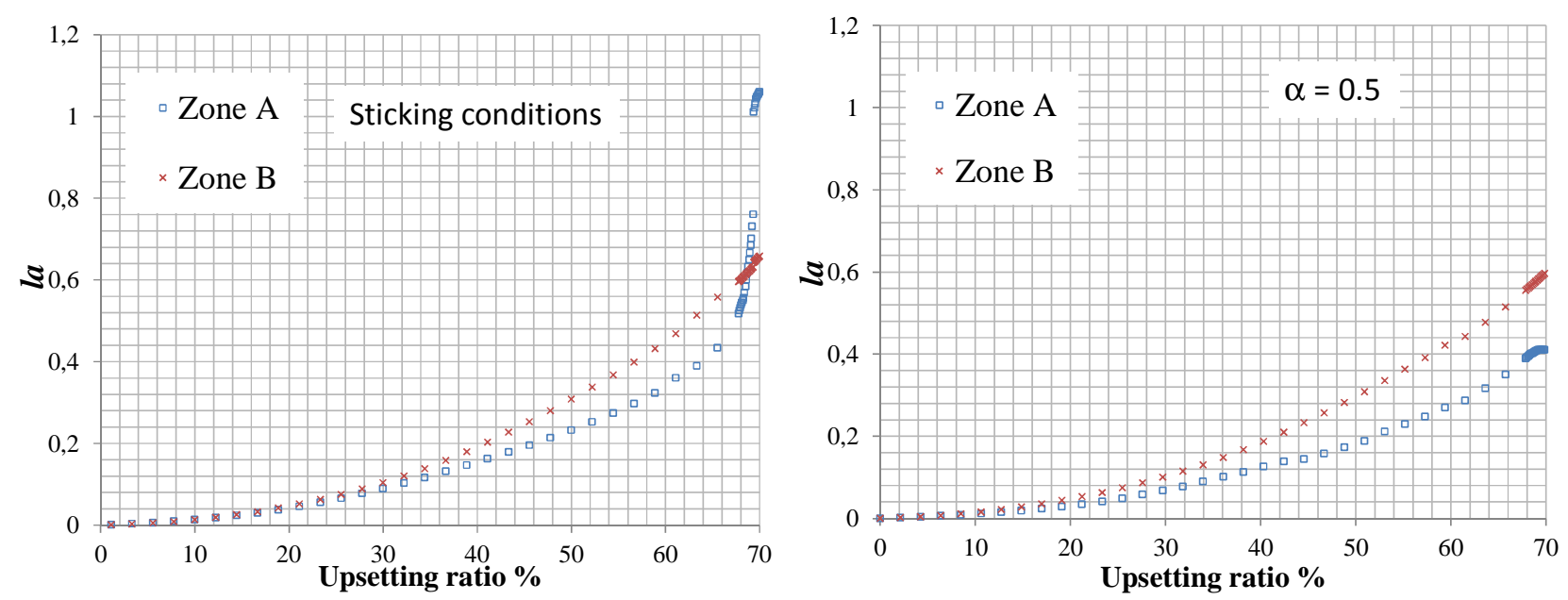

Fig. 10 Evolution of the indicator $L a$ for simulation corresponding to different friction conditions

For simulations performed with viscoplastic friction conditions, $L a$ remains lower in Zone A than in Zone B. This explains why circumferential cracks are only observed for upsetting tests with striated dies.

\section{Conclusions and perspective}

The research proposes to characterize the hot forging of weld cladded billet by hot upsetting test. A parametric study of upsetting test concerning the friction conditions at die/billet contact is carried out by slab model and finite element simulation. The application involves the case of stainless steel cladded on carbon steel.

In experimental tests, two types of cracks occur: longitudinal crack and circumferential crack. The latter occurs with striated die (equivalent to sticking condition). The curve of forging effort as function of upsetting ratio is typical for upsetting test. Friction has same effect on forging effort as for the upsetting test of mono-material billet.

A slab model is developed considering a visco-plastic friction law at die/billet contact. It permits getting the analytical expression of forging effort as function of upsetting ratio and certain processing parameters such as friction coefficients.

With Latham and Cockcroft Criterion, the finite element simulation allows predicting the possible position of crack observed experimentally regardless of the accuracy of the geometrical modeling of the substrate/cladded layer interface. More precisely, it seems unnecessary to take into account the periodic aspect of the substrate/cladding interface to predict overall material distribution, the forging effort and the crack occurrence. Wavy morphology should be considered to obtain more accurate cladding thicknesses.

The circumferential crack is specific to cladded billet due to overall mechanical interaction between the substrate and the cladded layer. This crack is the result of the lack of hot ductility of the cladded material, the initial material distribution and the hot forging process parameters like friction. 
The results obtained by upsetting test could be the base for identification of the behavior law of the constitutive material of the cladded layer. Indeed, this last one is the result of the solidification of a mix of the filler material and the substrate and is a priori unknown.

Further investigations have to be conducted about the evolution of the cladded microstructure during forming and subsequent cooling. Residual stresses within the cladded layer as result of the thermal expansion difference between the substrate and the cladded layer have to be considered.

\section{References}

[1] G. Mochnal. Forging of Stainless Steels, ASM Handbook, Vol14A, (2005) 261-268.

[2] B. Vamsi Krishna, P. Venugopal, K. Prasad Rao. Analysis of deformation during simultaneous plastic deformation of dissimilar powder metallurgical preforms. Powder Technology 146 (2004) 1337-146.

[3] B.V. Krishna, P. Venugopal, K.P. Rao. Co-extrusion of dissimilar sintered P/M preforms-an explored route to produce bimetallic tubes. Mater Sci Eng A (2005) 407:77-83.

[4] M. Şimşir, L.C. Kumruoğlu, A. Özer. An investigation into stainless steel/structural-alloy-steel bimetal produced by shell mould casting. Materials and Design 30 (2009) 264-270.

[5] J. Domblesky, F. Kraft, B. Druecke, B. Sims. Welded preforms for forging. Journal of Materials Processing Technology 171(2006) 141-149.

[6] J. Domblesky, F. Kraft. Mettalographic evaluation of welded forging preforms. Journal of Materials Processing Technology 191 (2007) 82-86.

[7] K.Essa, I. Kacmarcik, P. Hartley, M. Plancak, D.Vilotic. Upsetting of bi-metallic ring billets. Journal of Materials Processing Technology 212 (2012) 817-824.

[8] M. Rafiq, L. Langlois, R. Bigot. Hot forming of a cladded component by automated GMAW process. AIP Conference Proceeding 1315 (2010); 866-871 